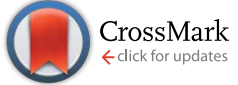

Cite this: RSC Adv., 2015, 5, 2536

Received 25th October 2014

Accepted 2nd December 2014

DOI: $10.1039 / c 4 r a 13126 f$

www.rsc.org/advances

\section{Synthesis of covalently bonded graphene oxide- iron magnetic nanoparticles and the kinetics of mercury removal $\uparrow$}

\begin{abstract}
Paul N. Diagboya, ${ }^{\text {ab }}$ Bamidele I. Olu-Owolabi ${ }^{b}$ and Kayode O. Adebowale ${ }^{b}$
Synergistically combined nanomaterials have been applied in various fields in materials science to improve the properties of nanocomposites. However, limited studies focus on the ability of such composites for water treatment. A graphene oxide (GO)-iron oxide $\left(\mathrm{Fe}_{3} \mathrm{O}_{4}\right)$ magnetic nano-particle composite (GOMNP) was synthesized and used to study the $\mathrm{Hg}^{2+}$ adsorption kinetics from aqueous solution at various temperatures. GO was attached to magnetic nanoparticles via the amine group of 3aminopropyltriethoxysilane which was attached the surface of $\mathrm{Fe}_{3} \mathrm{O}_{4}$. The GOMNP nano-composite had a $\mathrm{Hg}^{2+}$ adsorption capacity of $16.6 \mathrm{mg} \mathrm{g}^{-1}$. IR spectra analysis showed that hydroxyl and carboxylate functional groups were mainly responsible for $\mathrm{Hg}^{2+}$ adsorption. Adsorption of $\mathrm{Hg}^{2+}$ by the GOMNP obeyed different adsorption mechanisms at varying adsorption temperatures. The Elovich kinetics model described the $\mathrm{Hg}^{2+}$ adsorption data better than any of the other three models tested. The GOMNP nano-composite is thus a promising nanosorbent for $\mathrm{Hg}^{2+}$ removal from aqueous solutions.
\end{abstract}

\section{Introduction}

The adverse impact of mercury $(\mathrm{Hg})$ on biota is well documented. It has been known to cause dysfunctional organs in humans such as in the digestive, reproductive, cardiovascular and nervous systems, kidney, brain and eye. ${ }^{\mathbf{1 , 2}}$ At minute concentrations of more than $6 \mathrm{ppb}$, mercury is considered very toxic. ${ }^{2,3} \mathrm{Hg}$ occurs in the environment mainly in the form of methyl mercury, and in this and its other environmental forms it is not essential for plants or animals. ${ }^{1}$ Soils and sediments are usually its final sink, and when in the environment elemental $\mathrm{Hg}$ is easily methylated and it can be readily absorbed by biota in this methylated form, thus accumulating in humans via the food chain..$^{\mathbf{1 4 5}}$ A vivid example of mercury poisoning was seen in the Minamata incidence in the 1950s in Japan.

Recent studies have reported increasing cases of $\mathrm{Hg}$ in the environment ${ }^{6}$ and in humans ${ }^{5}$ especially in Asia due to the recent boom in industrial activities in this region. Anthropogenic emissions are either from intentional uses or as byproduct of other activities. At present, coal combustion represents a substantial source of $\mathrm{Hg}$ to the environment, ${ }^{7}$ and about half of current emissions are from Asia. Other

${ }^{a}$ National Center for Nanoscience and Technology, Beijing 100190, China. E-mail: pauldn2@yahoo.com; Tel: +862348038052553

${ }^{b}$ Department of Chemistry, University of Ibadan, Ibadan, Nigeria

$\dagger$ Electronic supplementary information (ESI) available: Further information on the synthesis of GO-MNP; descriptions of materials and methods used; BET diagram; and the Elovich kinetics isotherms at 20, 30, and $40{ }^{\circ} \mathrm{C}$. See DOI: $10.1039 / \mathrm{c} 4 \mathrm{ra13126f}$ sources include industrial processes such as cement and chlor-alkali productions, and mining applications, including artisanal and small-scale gold mining. ${ }^{6} \mathrm{Hg}$ in the environment finds its way into water and subsequently to soil where it is readily absorbed by aquatic organisms such as fishes and plants, respectively. Hence, reducing the quantity of mercury in effluents before discharge is necessary to reduce the amount of $\mathrm{Hg}$ that gets into the environment, and subsequent accumulation in biota.

The unique structural and functional properties associated with graphene oxide (GO), such as its high mechanical strength $\left(>1060 \mathrm{GPa}\right.$ ), theoretical surface area (about $\left.2600 \mathrm{~m}^{2} \mathrm{~g}^{-1}\right)$, and the presence of hydroxyl and carboxylic groups are important characteristics that make graphene oxide containing materials suitable for environmental applications. ${ }^{8}$ For instance some authors have employed these properties for adsorption of biphenol $\mathrm{A}^{\mathbf{9}}$ and arsenic, ${ }^{\mathbf{1 0}, 11}$ while others have employed the unique chemical and physical properties of iron magnetic nanoparticles together with other materials in the removal of some toxic substances from solution. ${ }^{\mathbf{8 , 1 2 , 1 3}}$ Iron magnetic nanoparticles have the ease of being removed from solution by magnetization. Iron magnetic nanoparticles synergistically combined with other nanomaterials have very promising capacities for water treatment.

With the foregoing in mind, the aim of this study was to covalently combine GO and iron magnetic nanoparticles into one chemical entity at reduced temperature, and employ this new material in the removal/adsorption of $\mathrm{Hg}^{2+}$ from aqueous solution. The adsorption data was explained kinetically. 


\section{Material and methods}

\subsection{Preparation of $\mathrm{GO}$ and synthesis of the APS- $\mathrm{Fe}_{3} \mathrm{O}_{4}$ hybrid nanoparticles}

The chemical exfoliation of natural flake graphite was carried out by modified Hummers' method in which a very long oxidation period was combined with a multi-cycle purification process $^{8}$ (see ESI†).

$\mathrm{Fe}_{3} \mathrm{O}_{4}$ nanoparticles (FNPs) were prepared using the chemical co-precipitation method by mixing $3.0 \mathrm{~mL}$ of $1 \mathrm{M} \mathrm{FeCl}_{3}$ and $1.0 \mathrm{~mL}$ of $2 \mathrm{M} \mathrm{FeCl}_{2}$ (ratio 2:1) solution in a $100 \mathrm{~mL}$ beaker containing a magnetic stirring bar. This mixture was continuously stirred under nitrogen while slowly adding $1.0 \mathrm{M}$ aqueous $\mathrm{NaOH}$ solution. The initial brown precipitate then turned to a black precipitate (magnetite) while still adding $\mathrm{NaOH}$. The stirrer was turned off and the magnetic stirring bar removed with a strong magnet. The magnetite formed was allowed to settle and the supernatant decanted. The solid was then washed with water and then ethanol accompanied by magnetic decanting after each washing. This is the iron oxide magnetic nanoparticles (FMNP).

$0.3 \mathrm{~g}$ of the synthesized FMNP was then dispersed in $20 \mathrm{~mL}$ ethanol by sonication. $3 \mathrm{~mL}$ (3-aminopropyl)-trimethoxysilane (APS) was added to the solution with continued sonication for $10 \mathrm{~min}$, and then incubated at $60{ }^{\circ} \mathrm{C}$ for $4 \mathrm{~h}$. Enough $\mathrm{N}$-(3dimethylaminopropyl)- $N$-ethylcarbodiimide hydrochloride (EDC) was added to make $100 \mathrm{mM}$ and the solution sonicated for $5 \mathrm{~min}$. The APS reaction is similar to that adopted by $\mathrm{He}$ et al. $^{14}$

\subsection{Synthesis of $\mathrm{GO}-\mathrm{Fe}_{3} \mathrm{O}_{4}$ nanoparticles}

GO magnetic nanoparticles (GOMNP) was synthesized from various concentrations of GO solutions. Solutions containing known amounts of GO were prepared in water and sonicated for $5 \mathrm{~min}$ (ESI - Table S1 $\dagger$ ). Specific volume of these solutions were added to the APS- $\mathrm{Fe}_{3} \mathrm{O}_{4}$ mixture above to obtain the final ' $x$ ' $\mathrm{mg} \mathrm{mL}^{-1} \mathrm{GO}$ concentration (' $x$ ' refers to GO concentration which could either be 0.5 or $1.0 \mathrm{mg} \mathrm{mL}^{-1}$; thus representing FMNP : GO concentration ratios of $2: 1$ and $1: 1$, respectively) (Table S1 $\dagger$ ). These concentration ratios are denoted as GOMNP-1 and GOMNP-2, respectively. The solutions were mixed, sonicated for $10 \mathrm{~min}$ and incubated at 65 ${ }^{\circ} \mathrm{C}$ for $8 \mathrm{~h}$. The GOMNP particles were then separated by magnetization, washed with water and ethanol thrice, and then freeze dried. Three control pots were set up containing: (a) all reagents but EDC (GOMNP); (b) only FMNP and APS (APS-FMNP); and, (c) FMNP and GO only (GOMNP-0). These were to ascertain the success of the FMNP-APS and FMNPAPS/GO reactions (Table S1†).

\subsection{Instrumental characterizations}

The GOMNP particles were characterized by Spectrum One Fourier transform infrared (FTIR) spectrometer (PerkinElmer Instruments Co. Ltd., USA), Pyris Diamond Thermogravimetric/differential thermal analyzer (PerkinElmer Instruments Co. Ltd., USA), Renishaw inVia Raman spectrometer (Renishaw plc, UK), Philips X'Pert PRO X-ray diffraction instrument (PANalytical B.V., Netherlands), and Micromeritics ASAP $2020 \mathrm{M}+\mathrm{C}$ accelerated surface area and porosimetry analyzer (Micromeritics Instrument Corporation, USA). Mercury adsorptions were monitored using Varian 710-ES ICP optical emission spectrometer (ES - S2†).

\subsection{Mercury adsorption}

Batch equilibrium adsorption procedure ${ }^{15}$ was used to determine the $\mathrm{Hg}^{2+}$ adsorption kinetics of GOMNP. The adsorptions were done at $\mathrm{pH} 5.0 \pm 0.2$ for three temperatures $-20,30$ and $40{ }^{\circ} \mathrm{C}$, in the time range of 5 to 180 minutes using a mercury solution concentration of $50 \mathrm{mg} \mathrm{L}^{-1}$ and $20 \mathrm{mg}$ of the GOMNP-1 each time. The $\mathrm{Hg}^{2+} / \mathrm{GOMNP}-1$ mixtures were incubated by shaking at the desired temperature in a temperature controlled shaker during the course of the adsorption experiment. The tubes were withdrawn from the shaker at the appropriate time interval, GOMNP-1 in solutions was separated and the $\mathrm{Hg}^{2+}$ concentration in the supernatant determined.

The quantity of $\mathrm{Hg}$ adsorbed in each case was calculated using eqn (1).

$$
q_{\mathrm{e}}=\frac{\left(C_{\mathrm{o}}-C_{\mathrm{e}}\right) V}{M}
$$

where $q_{\mathrm{e}}, C_{\mathrm{o}}$ and $C_{\mathrm{e}}$ are the amount of $\mathrm{Hg}$ adsorbed $\left(\mathrm{mg} \mathrm{g}^{-1}\right)$, the initial and final $\mathrm{Hg}$ concentrations in the solution $\left(\mathrm{mg} \mathrm{L}^{-1}\right)$, respectively; and $V(\mathrm{~mL})$ and $M(\mathrm{~g})$ are the volume of solution and mass of GOMNP-1 used for each adsorption, respectively.

The simplified linear equations of Lagergren pseudo-firstorder - PFO (eqn (2)), pseudo second-order - PSO (eqn (3)) rate models as well as the Elovich (eqn (4)) and intra-particle diffusion $^{16}$ (eqn (5)) kinetics models were used to describe the adsorption data.

$$
\begin{gathered}
\log \left(q_{\mathrm{e}}-q_{t}\right)=\log q_{\mathrm{e}}-\frac{k_{1}}{2.303} t \\
\frac{t}{q_{t}}=\frac{1}{k_{2} q_{\mathrm{e}}^{2}}+\frac{t}{q_{\mathrm{e}}} \\
q_{t}=\frac{1}{\beta} \operatorname{In}(\alpha \beta)+\frac{1}{\beta} \operatorname{In}(t) \\
q_{t}=k_{\mathrm{i}}\left(t^{1 / 2}\right)+C
\end{gathered}
$$

where $q_{\mathrm{e}}$ and $q_{t}$ are $\mathrm{Hg}$ adsorbed $\left(\mathrm{mg} \mathrm{g}^{-1}\right)$ at equilibrium and at time $t$, respectively; and $k_{1}\left(\mathrm{~min}^{-1}\right)$ and $k_{2}\left(\mathrm{~g} \mathrm{gg}^{-1} \mathrm{~min}^{-1}\right)$ are the rate constants of the PFO and PSO, respectively. The $q_{\mathrm{e}}$ and rate constants were calculated from the slope and intercept of the plots of $\log \left(q_{\mathrm{e}}-q_{t}\right)$ vs. $t$; and $\frac{t}{q_{t}} v s . t$ for PFO and PSO, respectively, $\alpha$ is the initial adsorption rate $\left(\mathrm{mg} \mathrm{g}^{-1} \min ^{-1}\right)$ and $\beta$ is the desorption constant $\left(\mathrm{g} \mathrm{mg}^{-1}\right)$ during any one experiment, and $C$ $\left(\mu \mathrm{g} \mathrm{g}^{-1}\right)$ values indicate the thickness of the boundary layer of $\mathrm{Hg}^{2+}$ ion adsorbed, and $k_{\mathrm{i}}\left(\mathrm{mg} \mathrm{g}^{-1} \mathrm{~min}^{-1 / 2}\right)$ is intra-particle diffusion rate constant of the control stage. 


\section{Results and discussion}

\subsection{Characterization}

The schematic synthesis of the iron magnetic nanoparticles (FMNP) and GO composite is shown in Fig. 1. The FMNP particles were first synthesized and then reacted with 3-aminopropyltriethoxysilane (APS), and subsequently GO sheets were attached via the amine group on the APS. This was similar to the modification reaction carried out by $\mathrm{He}$ et al. ${ }^{14}$ Fig. 2a shows the IR spectra of GO and the various modified GO-MNPs. The characteristic peaks of pristine GO for hydroxyl groups, $-\mathrm{C}=\mathrm{O}$ bond of the amide-I, carboxylate vibrations, and $-\mathrm{C}-\mathrm{O}$ band of carboxylic acids were observed at 3436, 1627, 1421, and $1068 \mathrm{~cm}^{-1}$, respectively. ${ }^{8}$ The IR spectra of various modified GOMNP were different from that of GO as shown in Fig. 2a suggesting that the treatment conferred new functional groups unto the GO. In addition to the observed peaks of pristine GO, distinct peaks originating after the treatments were observed in the GOMNP as well as the APS-FMNP. The hydroxyl and amide I band stretch of $\mathrm{C}=\mathrm{O}$ were observed at around 3436 and 1628 $\mathrm{cm}^{-1}$, respectively. However, the GO band at $1068 \mathrm{~cm}^{-1}$ disappeared with the appearance of three new bands at 890, 1051 and $1129 \mathrm{~cm}^{-1}$ indicating the presence of $\mathrm{Si}-\mathrm{O}$ from APS in the newly formed structure. The band around $1330 \mathrm{~cm}^{-1}$ was attributed to $-\mathrm{CH}_{2}-$ scissor of the aliphatic propyl chain of the APS while additional bands around 1491 and $1566 \mathrm{~cm}^{-1}$ was assigned to the amine $-\mathrm{C}-\mathrm{N}-$ and $-\mathrm{NH}$ bend linking APS and
GO. ${ }^{15}$ The peak close to $600 \mathrm{~cm}^{-1}$ was ascribed to absorption by the $\mathrm{Fe}-\mathrm{O}$ bond of the iron oxide. These bands indicate a covalent linkage between GO and the FMNP. ${ }^{17}$

TGA curves of GO, and the various FMNP modifications are shown in Fig. 2b. The curve for FMNP showed little weight loss about $3 \%$ below $250{ }^{\circ} \mathrm{C}$. Comparing the FMNP with the pristine GO, it was observed that GO showed a far lower thermal stability and much higher weight loss losing about $60 \%$ of its original weight before $380{ }^{\circ} \mathrm{C}$. This weight loss was due to moisture loss at the initial temperature, and later on the pyrolysis and decomposition of the labile oxygen-containing functional groups such as $-\mathrm{CO},-\mathrm{OH}$ and $-\mathrm{COOH}$ attached to $\mathrm{GO}$ resulting in the loss of $\mathrm{CO}, \mathrm{CO}_{2}$ and steam. Further weight loss, which was steady $(\sim 5 \%)$ occurred thereafter in the temperature range of about 400 to $800{ }^{\circ} \mathrm{C}$, and this may be attributed to removal of more stable functional groups at higher temperatures. However, modification of the GO with FMNP reduced the weight loss. The weight loss was between 15 to $25 \%$ depending on the effectiveness of the reaction between GO and FMNP. The higher the quantity of GO attached to FMNP, the more the weight loss. Though magnetic separation test result (Fig. 2d) showed that it is possible to react APS-FMNP and GO to obtain GOMNP, comparison of the TGA data of GOMNP, GOMNP-1, and GOMNP-2 showed that higher quantity of GO (up to $5 \%$ more) can be attached to FMNP in the presence of EDC; thus, more GO was linked per gram FMNP in the presence of EDC.

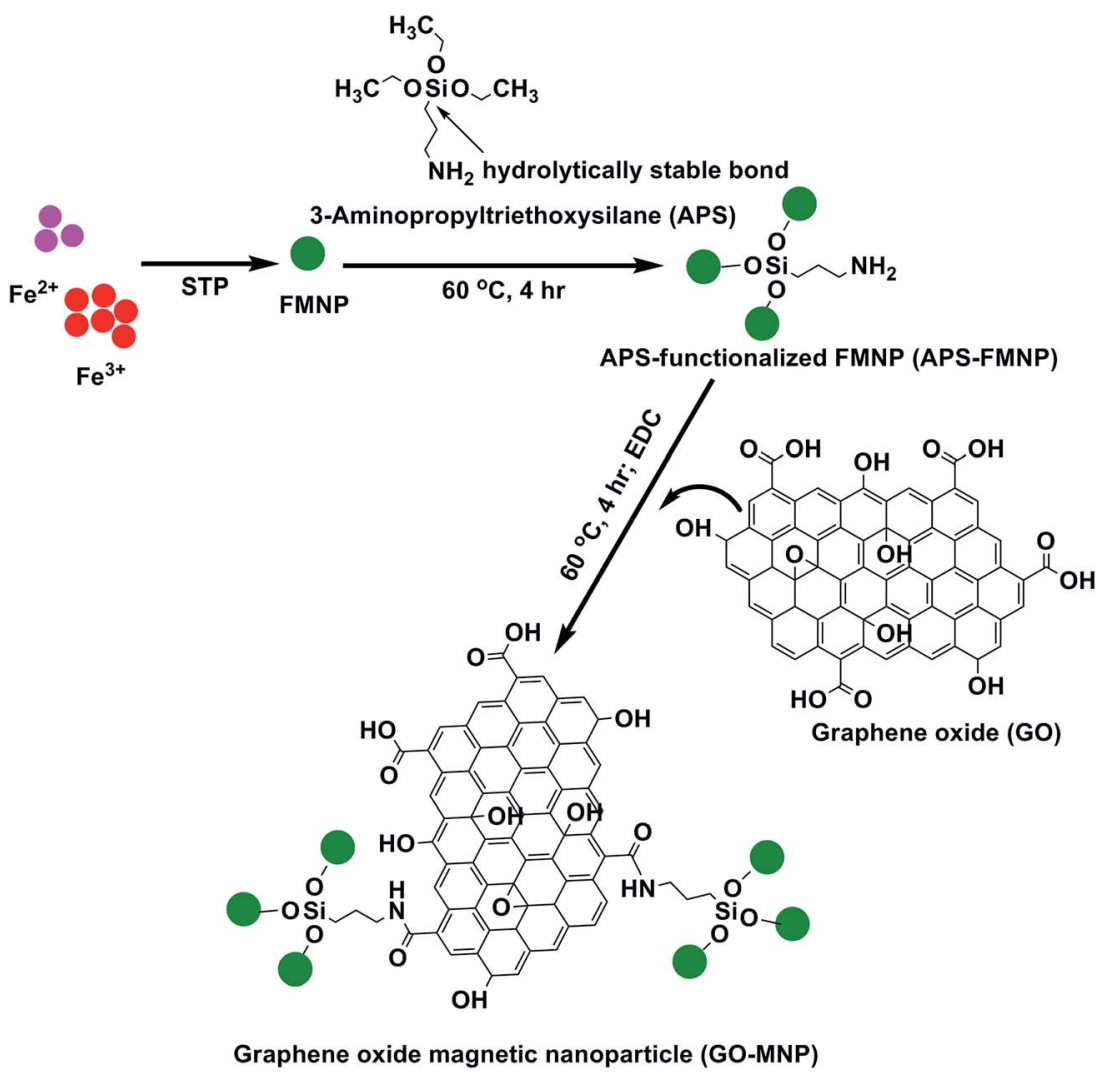

Fig. 1 Schematic synthesis of GOMNP. 

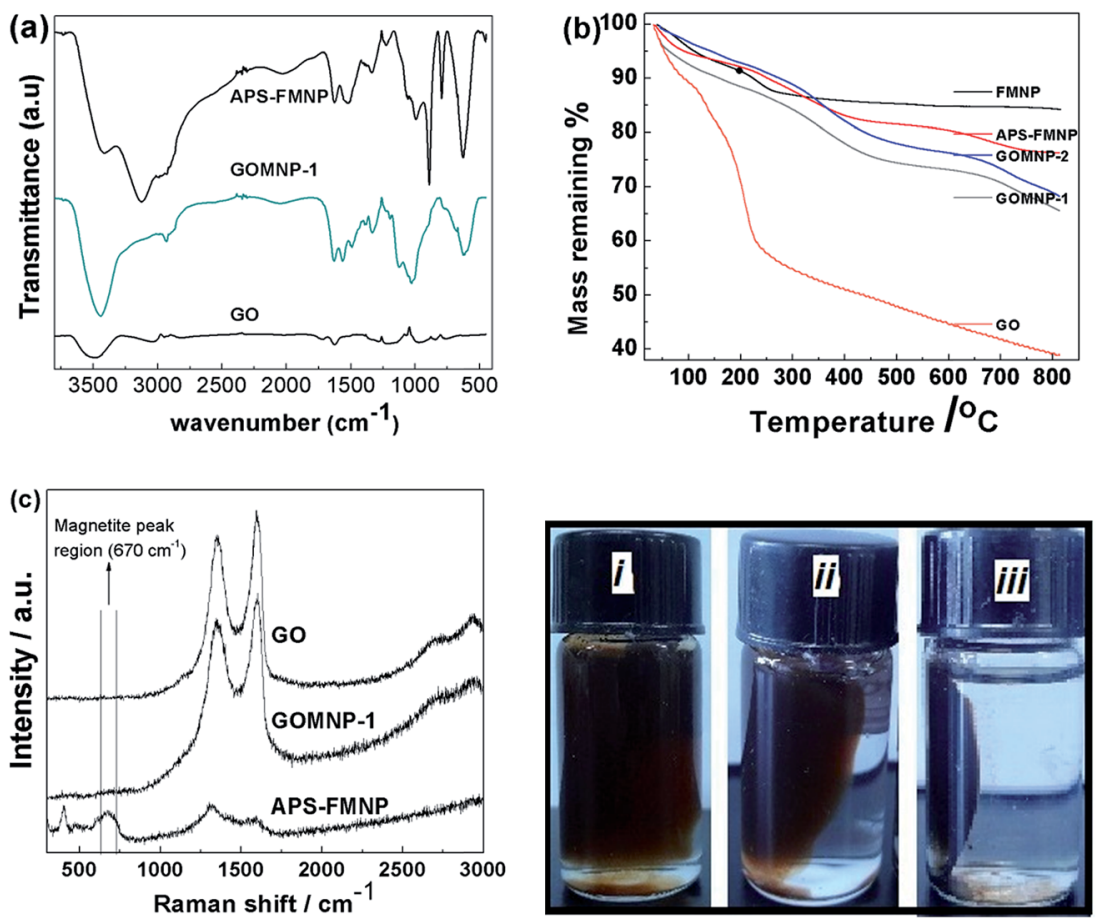

Fig. 2 (a) IR spectra of the various synthesized materials; (b) TGA of the GOMNP materials; (c) Raman spectra of GO, APS-FMNP, and GOMNP; (d) magnetic separation from solution test (i) GOMNP-0, (ii) GOMNP and (iii) GOMNP-1.

Raman spectroscopy is another method for the identification of the presence of carbonaceous materials as well as iron oxide phase in a compound because of the varying vibrational fingerprints of magnetite, maghemite and hematite. Raman spectra of the GO and the modified GOMNPs showed the presence of the added carbonaceous materials in the GOMNPs (Fig. 2c). GO and GOMNP-1 displayed the well known D- and Gbands associated with GO materials at around 1354 and 1600 $\mathrm{cm}^{-1}$, respectively. The D peaks were attributed to the presence of condensed benzene regions in the graphene structure, while the $\mathrm{G}$ peaks were evidence of $\mathrm{sp}^{2}$ bonded carbon that is present in planar sheet configurations which includes $\mathrm{sp}^{2} \mathrm{C}=\mathrm{C}$ stretch vibrations. $^{8}$ The spectra of APS-FMNP and GOMNP showed additional peak at $670 \mathrm{~cm}^{-1}$ which corresponds to that of magnetite. The BET surface areas and porosities of GO, FMNP and GOMNP-1 were determined as 56, 125 and $214 \mathrm{~m}^{-2} \mathrm{~g}^{-1}$, respectively; and adsorption average pore diameters of 4.8, 13.7, and $13.1 \mathrm{~nm}$, respectively (ESI - Fig. S1†). The observed increases in surface area of these new materials were attributed to the rigid nature of the FMNP particles which reduces stacking of the GO sheets; and hence increases the surface area.

To ascertain whether the magnetic property of the FMNP were transferred to GOMNP by the FMNP attachment to the GO surface via the amine group of the 3-aminopropyltriethoxysilane (APS), GOMNP, GOMNP-0 and GOMNP-1 were subjected to magnetic separation test. If the GO sheets are attached to the FMNP, separation will be perfect in the presence of external magnetic field. After $20 \mathrm{~min}$, it was observed that GOMNP and GOMNP-1 were separated as shown in Fig. 2d. However, the GOMNP-0 (Fig. 2d(i)) remained unseparated just like before the application of the external magnetic field and no clear solution was observed indicating that GO-magnetic hybrid particles were not formed like in the GOMNP and GOMNP-1. For GOMNP (Fig. 2d(ii)) partial separation was observed, while GOMNP-1 (Fig. 2d(iii)), on the other hand, showed a complete separation. This was an indication that the FMNPs were attached to the GO and were separated along with the GO sheets. GO were covalently attached to the FMNP via amide bonds which were formed between the amine group of APS and the carboxylic group of the GO sheets. He et al. ${ }^{14}$ have reported a similar reaction using APS.

\subsection{Adsorption kinetics of mercury}

Batch equilibrium adsorption procedure was used to study the $\mathrm{Hg}^{2+}$ adsorption kinetics of GOMNP-1 at pH $5.0 \pm 0.2$ and at 20, 30 , and $40^{\circ} \mathrm{C}$ using $\mathrm{Hg}^{2+}$ concentration of $50 \mathrm{mg} \mathrm{L}^{-1}$ and $20 \mathrm{mg}$ of GOMNP-1 in the time range of 5 to 180 minutes. Adsorption kinetics study is important because it gives information on the rate of the adsorption of a particular sorbate under a set of prescribed conditions. Preliminary investigations conducted to compare the $\mathrm{Hg}^{2+}$ adsorption capacity of pristine $\mathrm{GO}$ and GOMNP-1 showed that GO has $\mathrm{Hg}^{2+}$ adsorption capacity of 2.9 $\mathrm{mg} \mathrm{g}^{-1}$ while GOMNP-1 has over 5 fold higher adsorption capacity. The adsorption time curve (Fig. 3a(i)) showed that $\mathrm{Hg}^{2+}$ adsorption equilibria were fast and this was reached within 120 minutes. Similar fast adsorption results have been reported in literature for graphene based materials. ${ }^{\mathbf{1 0 , 1 7 , 1 8}}$ The difference in adsorption capacities of GO and GOMNP-1 is an indication that in addition to the adsorption sites on the GO sheets provided by the presence of the carboxylic (-COO) and 

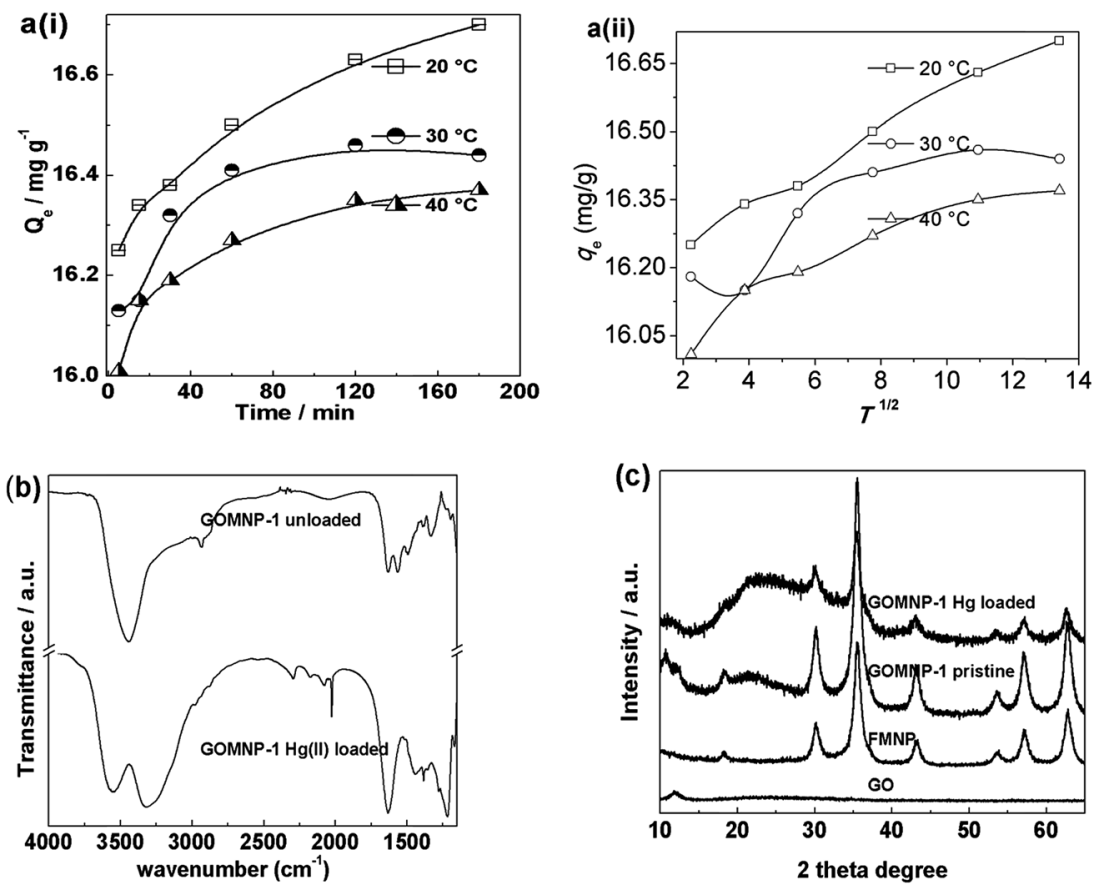

Fig. 3 (a)(i) Effect of time on $\mathrm{Hg}^{2+}$ adsorption by GOMNP-1; (a)(ii) non-linear curves of the intra-particle diffusion kinetics model at the various temperatures studied; (b) IR spectra of $\mathrm{Hg}^{2+}$ loaded and pristine GOMNP; (c) XRD patterns of GO, FMNP, pristine GOMNP-1, and GOMNP-1 loaded with $\mathrm{Hg}^{2+}$.

hydroxyl (-OH) functional groups, the FMNP particles magnetic acted as sorbent for $\mathrm{Hg}^{2+}$ in solution. The significant difference in the $\mathrm{Hg}^{2+}$ adsorption capacities of both GO and GO/FMNP composites is also testimony to the success of attaching GO to the FMNP particles. Fig. 3a(i) also showed that increase in $\mathrm{Hg}^{2+}$ solution temperature from 20 to $40{ }^{\circ} \mathrm{C}$ did not lead to a corresponding increase in adsorption capacity, but that adsorption capacity is inversely proportional to the temperature. The adsorption trend is $20^{\circ} \mathrm{C}>30^{\circ} \mathrm{C}>40^{\circ} \mathrm{C}$. The negative effect of temperature on the adsorption of $\mathrm{Hg}^{2+}$ by the GOMNP-1 material may be an indication that the process occurs mainly by physisorption and is exothermic. Vidic and $\mathrm{Siler}^{2}$ and Olson et al. ${ }^{7}$ have also reported similar temperature effect on $\mathrm{Hg}^{2+}$ adsorption. This observation could be explained thus: $\mathrm{Hg}$ metal is liquid and volatile at room temperature; increasing the adsorption medium temperature increases the kinetic energy of the molecules in solution and subsequently the molecules moves away from the adsorption surfaces, and hence the observed reduction in adsorption with increase in temperature.

The $\mathrm{Hg}^{2+}$ adsorption data at 20,30 , and $40{ }^{\circ} \mathrm{C}$ was fitted to four kinetics models: the pseudo-first order, pseudo-second order, Elovich and intra-particle diffusion kinetics models (Table 1). These models were used to describe the adsorption as well as predict the adsorption mechanism(s) involved in the uptake of $\mathrm{Hg}^{2+}$ by GOMNP-1. Data from Table 1 indicated that the Lagergren pseudo-first order kinetics described the adsorption better than the Lagergren pseudo-second order kinetics model as revealed by the correlation coefficients $\left(r^{2}\right)$ values. However, none of these models were able to predict the adsorption capacity of the GOMNP-1 material, nor could they be used to confidently predict the adsorption mechanism that controlled the adsorption process of $\mathrm{Hg}^{2+}$ on GOMNP-1.

The $r^{2}$ values of the Elovich kinetics model on the other hand showed that the adsorption data fitted the model better than the pseudo-first order and pseudo-second order kinetics models. The Elovich model was able to predict the adsorption capacity of the GOMNP for the sorbate. This adsorption model which originated from chemical reaction kinetics suggested that there was some degree of boundary layer control between the $\mathrm{Hg}^{2+}$ ions and the GOMNP-1 surface active adsorption sites since the curves does not pass through the origin (ESI Fig. S2(a), (b) and (c) †). This boundary layer control is related to

Table 1 Adsorption kinetics model parameters at 20,30 , and $40^{\circ} \mathrm{C}$

\begin{tabular}{lllll}
\hline & & \multicolumn{3}{l}{ Temperatures } \\
\cline { 3 - 5 } Kinetics model & Model parameters & $20{ }^{\circ} \mathrm{C}$ & $30{ }^{\circ} \mathrm{C}$ & $40{ }^{\circ} \mathrm{C}$ \\
\hline \multirow{2}{*}{ Pseudo-first-order } & $q_{\mathrm{e}}\left(\mathrm{mg} \mathrm{g}^{-1}\right)$ & 2.76 & 2.08 & 1.67 \\
& $k_{1}\left(\mathrm{~min}^{-1}\right)$ & 0.007 & 0.002 & 0.002 \\
& $r^{2}\left(\mathrm{~m} \mathrm{~g}^{-1}\right)$ & 0.909 & 0.720 & 0.869 \\
Pseudo-second-order & $q_{\mathrm{e}}\left(\mathrm{mg}^{-1}\right.$ & - & - \\
& $k_{2}\left(\mathrm{~g} \mathrm{mg}^{-1} \mathrm{~min}^{-1}\right)$ & - & - & - \\
Elovich & $r^{2}\left(\mathrm{mg} \mathrm{g}^{-1}\right)$ & 0.922 & 0.522 & 0.154 \\
& $q_{\mathrm{e}}\left(\mathrm{mg}^{2}\right.$ & 16.61 & 16.43 & 16.33 \\
& $\beta$ & 7.87 & 10.75 & 10.00 \\
Intra-particle diffusion & $r^{2}\left(\mathrm{mg} \mathrm{g}^{-1}\right)$ & 0.950 & 0.851 & 0.990 \\
& $k_{\mathrm{i}}$ & 16.17 & 16.12 & 16.00 \\
& $r^{2}$ & 0.04 & 0.03 & 0.03 \\
& & 0.990 & 0.800 & 0.917
\end{tabular}

${ }^{a}$ Values are less than 0.001 
Table 2 Comparison of $\mathrm{Hg}^{2+}$ adsorption $q_{\mathrm{e}}$ on GOMNP-1 with GO modified with metal/metal oxide

\begin{tabular}{lcl}
\hline Adsorbent & $q_{\mathrm{e}}\left(\mathrm{mg} \mathrm{g}^{-1}\right)$ & Reference \\
\hline GOMNP & 16.6 & Present study \\
RGO-MnO & & (Sreeprasad et al., 2011) $)^{17}$ \\
RGO-Ag & 9.0 & (Sreeprasad et al., 2011) \\
GO & 9.0 & Present study
\end{tabular}

the rate determining mechanism and involved valence electron forces through sharing of electrons between the $\mathrm{Hg}^{2+}$ and GOMNP-1 surface active adsorption sites. ${ }^{19}$

The adsorption kinetic data were further processed to determine whether intra-particle diffusion was the rate limiting step of the adsorption and to find rate parameters for the model (Table 1 and Fig. 3a(ii)). The $r^{2}$ values of the intra-particle diffusion model were all relatively better than those of other studied models $(>0.800)$ and the $C\left(\mu \mathrm{g} \mathrm{g}^{-1}\right)$ values of this model, an indication of the boundary layer thickness of $\mathrm{Hg}^{2+}$ on the adsorbent surface, showed that the $\mathrm{Hg}^{2+}$ removal process was mainly surface phenomenon (adsorption) occurring by physisorption. This conclusion was reached because the quantity of $\mathrm{Hg}^{2+}$ on the adsorbent surface significantly correlated to the experimental values. At lower temperature $\left(20^{\circ} \mathrm{C}\right)$, the $r^{2}$ value of the pseudo-second-order kinetics was higher than that of the pseudo-first-order kinetics. The high $r^{2}$ values of intra-particle diffusion and pseudo-second-order kinetics models support the assertion that the overall rate of the adsorption process was controlled by more than one-step as observed from the nonlinear curves of Fig. 3a(ii). However, as ambient temperature increased, the adsorption mechanism changed; the $r^{2}$ values of the intra-particle diffusion model at higher temperatures (20 and $30^{\circ} \mathrm{C}$ ) were close to unity and also significantly higher than those of both the pseudo-first and second-order kinetics. This indicated that as temperature increased the intra-particle diffusion was the predominant rate determining step of $\mathrm{Hg}^{2+}$ adsorption on the GOMNP-1 surface. This was evident in the shapes of the intra-particle diffusion model curves in Fig. 3a(ii) at 30 and $40{ }^{\circ} \mathrm{C}$. Hence, different kinetics mechanisms control $\mathrm{Hg}^{2+}$ at different solution temperatures.

The infra-red spectra of the $\mathrm{Hg}^{2+}$-loaded and unloaded GOMNP-1 were compared (Fig. 3b). It was observed that the $\mathrm{Hg}^{2+}$-loaded GOMNP-1 spectra showed shifts in spectra peaks (especially for the carboxylate and hydroxyl groups) as well as new spectra bands. The amide-I band at 1628 shifted to 1632 $\mathrm{cm}^{-1}$, while the hydroxyl vibration at $1491 \mathrm{~cm}^{-1}$ shifted to 1442 $\mathrm{cm}^{-1}$. However, there was a peak split at $3436 \mathrm{~cm}^{-1}$ resulting into two new peaks observed at 3324 and $3551 \mathrm{~cm}^{-1}$. These peaks were attributed to the adsorption of $\mathrm{Hg}^{2+}$ on the hydroxyl functional group. These peak shifts and new bands associated with hydroxyl vibrations and amide-I bands, have been attributed to the counter ions changes associated with these functional groups anions after the adsorptions of $\mathrm{Hg}^{2+}$; and are indications of the role played by these functional groups on the GOMNP-1 surface.
The crystal phase compositions of the pristine FMNP, GO, GOMNP-1 as well as the $\mathrm{Hg}^{2+}$ loaded GOMNP-1 were studied by powder X-ray diffraction (Fig. 3c). The analysis of X-ray patterns revealed structural changes that occurred after specific reactions/adsorption. GO (Fig. 3c) showed a strong peak around $2 \theta=12^{\circ}$ and a weak broad peak around $23^{\circ}$. Both peaks indicated the presence of functional groups containing oxygen which was formed during the strong graphite oxidation process. $^{20}$ The pristine GOMNP-1 XRD diffractions (Fig. 3c) showed the characteristic peaks associated with the presence of pure spinal structures of $\mathrm{Fe}_{3} \mathrm{O}_{4}$ (Fig. 3c) at $2 \theta$ values of 30.1, $35.5,43.1,53.6,57.1$ and $62.7^{\circ}$, with the respective indices of (220), (311), (400), (422), (511), and (440), as well as the GO diffraction bands discussed earlier. These observations above indicated that the formation of the GOMNP-1 did not result in phase change of $\mathrm{Fe}_{3} \mathrm{O}_{4}$. As similarly observed in the IR spectra, there was a shift in the diffraction pattern of the GOMNP-1 after $\mathrm{Hg}^{2+}$ adsorption (Fig. 3c). All FMNP and GO $2 \theta$ observed bands were also present in the $\mathrm{Hg}^{2+}$-loaded GOMNP-1. However, the GO diffraction band around $2 \theta=23^{\circ}$ became broadened. This was attributed to the presence of $\mathrm{Hg}^{2+}$ which caused a distortion in the crystal structure of the GOMNP-1 within that band area; and since that band area has been attributed to GO; this suggested that $\mathrm{Hg}^{2+}$ adsorptions occurred on the GO sheets.

Comparisons of GOMNP-1 $\mathrm{Hg}^{2+}$ adsorption capacity, $q_{\mathrm{e}}$, to those of GO modified with metal/metal oxide in literature (Table 2) showed that the GOMNP-1 had a better $q_{\mathrm{e}}$ value.

\section{Conclusion}

The kinetics of $\mathrm{Hg}^{2+}$ adsorption by graphene oxide-iron oxide magnetic nano-particles composite (GOMNP) was investigated. Iron oxide magnetic nano-particles was attached to the graphene oxide (GO) using 3-aminopropyltriethoxysilane at a considerably low temperature. The GO-magnetic nanoparticles composite has over 5 -fold higher adsorption capacity than the pristine GO sheets. Increase in temperature had a negative effect on the adsorption of $\mathrm{Hg}^{2+}$ by the composite: $20^{\circ} \mathrm{C}>30^{\circ} \mathrm{C}$ $>40{ }^{\circ} \mathrm{C}$. The Elovich kinetics model described the $\mathrm{Hg}^{2+}$ adsorption better than pseudo first and second order kinetics models. $\mathrm{Hg}^{2+}$ adsorption kinetics mechanism at $20{ }^{\circ} \mathrm{C}$ is predominantly the pseudo-second order kinetics while at higher temperatures the mechanism was predominantly intraparticle diffusion. IR spectra analysis showed that hydroxyl and carboxylate functional groups were mainly responsible for $\mathrm{Hg}^{2+}$ adsorption. XRD diffraction patterns also confirmed the involvement of GO functional groups in the adsorption. GOMNP is thus a promising nanosorbent for $\mathrm{Hg}^{2+}$ removal from aqueous solutions.

\section{Acknowledgements}

The financial support of the National Science Foundation of China (Grants no. 91023001 and 60911130231) and the Chinese Academy of Sciences (Knowledge Innovation Program, Grant no. KJCX2-YW-H21) is acknowledged. We also acknowledge the supports of Chief S.L. Edu/Chevron Research grant (Nigeria 
Conservation Foundation) Nigeria, and the World Academy of Sciences (TWAS), Trieste Italy and the Chinese Academy of Sciences (CAS), China for the award of CAS-TWAS Postgraduate Fellowship (FR number: 3240255024) to P. N. Diagboya; late Rebecca A. Okoh, and Victor P. O. Okoh Department of Estate Management, Yaba College of Technology, Lagos Nigeria.

\section{References}

1 Y. S. Hong, Y. M. Kim and K. E. Lee, J Prev Med Public Health, 2012, 45, 353-363.

2 R. D. Vidic and D. P. Siler, Carbon, 2001, 39, 3-14.

3 WHO (World Health Organization), Guidelines for DrinkingWater Quality, World Health Organization, Geneva, 4th edn, 2011, ch. xxiii, p. 541.

4 Y. D. Jing, Z. L. He and X. E. Yang, Chemosphere, 2007, 69, 1662-1669.

5 S. R. Shin and A. L. Han, Korean J Fam Med., 2012, 33, 320325.

6 E. M. Sunderland and N. E. Selin, Environ. Health, 2013, 12, 2.

7 E. S. Olson, S. J. Miller, R. K. Sharma, G. E. Dunham and S. A. Benson, J. Hazard. Mater., 2000, 74, 61-79.

8 P. N. Diagboya, B. I. Olu-Owolabi, D. Zhou and B. H. Han, Carbon, 2014, 79, 174-182.

9 J. Xu, L. Wang and Y. Zhu, Langmuir, 2012, 28, 8418-8425.
10 V. Chandra, J. Park, Y. Chun, J. W. Lee, I. C. Hwang and K. S. Kim, ACS Nano, 2010, 4, 3979-3986.

11 A. K. Mishra and S. Ramaprabhu, Desalination, 2011, 282, 39-45.

12 S. R. Kanel, D. Nepal, B. Manning and H. Choi, J. Nanopart. Res., 2007, 9, 725-735.

13 I. N. Savina, C. J. English, R. L. Whitby, Y. Zheng, A. Leistner and S. V. Mikhalovsky, et al., J. Hazard. Mater., 2011, 192, 1002-1008.

14 F. He, J. Fan, D. Ma, L. Zhang, C. Leung and H. L. Chan, Carbon, 2010, 48, 3139-3144.

15 P. N. Diagboya, B. I. Olu-Owolabi and K. O. Adebowale, J. Environ. Manage., 2014, 146, 42-49.

16 B. I. Olu-Owolabi, P. N. Diagboya and K. O. Adebowale, J. Environ. Manage., 2014, 137, 1-9.

17 T. S. Sreeprasad, S. M. Maliyekkal, K. P. Lisha and T. Pradeep, J. Hazard. Mater., 2011, 186, 921-931.

18 V. Chandra and K. S. Kim, Chem. Commun., 2011, 47, 39423944.

19 B. I. Olu-Owolabi, P. N. Diagboya and W. C. Ebaddan, Chem. Eng. J., 2012, 195-196, 270-275.

20 C. Wu, Q. Cheng, S. Sun and H. B. Han, Carbon, 2012, 50, 1083-1089. 